\title{
FAKTOR YANG MEMPENGARUHI LITERASI KESEHATAN PADA \\ PENDERITA DIABETES MELITUS TIPE 2 \\ DI KOTA MANADO
}

\author{
Juwita Moreen Toar \\ Program Studi Ilmu Keperawatan, Fakultas Kedokteran, Universitas Sam Ratulangi, Indonesia \\ Email: ns.juwita@unsrat.ac.id
}

\begin{abstract}
Abstrak
Literasi kesehatan memiliki peranan penting dalam pemberdayaan masyarakat Literasi kesehatan yang tinggi akan memampukan seseorang menggunakan informasi kesehatan yang tepat dalam meningkatkan atau mempertahankan kesehatannya khususnya pada penyakit Diabetes Melitus (DM). Berbagai studi juga menyatakan bahwa literasi kesehatan berhubungan erat dengan status kesehatan seseorang. Melihat dampak literasi kesehatan yang cukup besar maka perlu diketahui faktor-faktor apa saja yang berhubungan dengannya. Tujuan Penelitian ini bertujuan untuk mengetahui tingkat literasi kesehatan pasien Diabetes Mellitus tipe 2 dan faktor-faktor yang berhubungan dengan tingkat literasi kesehatan tersebut. Metode Penelitian ini merupakan penelitian kuantitatif dengan desain cross sectional. Subjek penelitian $(\mathrm{N}=52)$ adalah peserta prolanis penderita Diabetes Mellitus tipe 2 yang berusia $\geq 45$ tahun. Pengumpulan data dilakukan melalui kuesioner dan lembar observasi. Teknik pengambilan sampel dilakukan secara purposive sampling. Analisis yang digunakan yaitu analisis chisquare. Hasil Hasil penelitian dengan menggunakan analisis chi-square menunjukkan bahwa ada hubungan antara usia dengan tingkat literasi kesehatan $(\mathrm{p}<0,05)$ sedangkan factor lainnya seperti jenis kelamin, etnis, bahasa, tingkat pendidikan, status pekerjaan, penghasilan, akses pelayanan kesehatan serta akses informasi kesehatan tidak memiliki hubungan dengan literasi kesehatan. Kesimpulan Faktor yang berhubungan dengan tingkat literasi kesehatan seseorang adalah usia.
\end{abstract}

Kata kunci : literasi kesehatan, diabetes mellitus, akses pelayanan kesehatan

\begin{abstract}
Health literacy has an important role in community empowerment. High health literacy will enable a person to use appropriate health information in improving or maintaining their health, especially in Diabetes Mellitus (DM). Various studies have also stated that health literacy is closely related to a person's health status. Seeing the large impact of health literacy, it is necessary to know what factors are related to it. Aim The aim of this study was to determine the level of literasi kesehatanof patients with Diabetes Mellitus type 2 and the factors related to the level of health literacy. Method This research is a quantitative study with a cross sectional design. The research subjects $(\mathrm{N}=52)$ were prolanis participants with type 2 Diabetes Mellitus who were $\geq 45$ years old. Data collection was carried out through questionnaires and observation sheets. The sampling technique was carried out by purposive sampling. The analysis used is the chi-square analysis. Results The results of the study using the chi-square analysis showed that there was a relationship between age and the level of health literacy $(\mathrm{p}<0.05)$, while other factors such as gender, ethnicity, language, education level, employment status, income, access to health services and access health information has no relationship with health literacy. Conclusion A factor related to a person's health literacy is age.
\end{abstract}

Keywords : health literacy, diabetes mellitus, health services access 


\section{PENDAHULUAN}

Keberhasilan pembangunan mengakibatkan transisi demografi dalam bidang kesehatan dimana terjadi peningkatan angka kesakitan karena penyakit degenerative yang dikaitkan dengan meningkatnya populasi lanjut usia (lansia) akibat usia harapan hidup yang tinggi (Kemenkes, 2013). Penyakit degenerative yang terus meningkat prevalensinya di seluruh dunia yaitu Diabetes Mellitus (DM). Faktor gaya hidup berperan penting dalam peningkatan kejadian DM (IDF, 2013). Memilih gaya hidup sehat, mengetahui cara mencari perawatan medis, dan mengambil keuntungan dari tindakan pencegahan mengharuskan orang memahami dan menggunakan informasi kesehatan. Kemampuan untuk mendapatkan, mengolah, dan memahami informasi kesehatan yang dibutuhkan untuk membuat keputusan kesehatan yang tepat dikenal sebagai literasi kesehatan (health literacy). Institute of Medicine (IOM) dalam Nutbeam (2000) mendefinisikan literasi kesehatan sebagai sejauh mana individu memiliki kapasitas untuk memperoleh, mengolah, dan memahami informasi dasar dan layanan yang dibutuhkan untuk membuat keputusan yang tepat tentang kesehatan mereka (Nielsen-Bohlman, Panzer, \& Kindig, 2004). Lierasi kesehatan yang rendah dianggap sebagai penghalang potensial untuk meningkatkan hasil kesehatan pada orang dengan diabetes dan kondisi kronis lainnya (Al Sayah, Majumdar, Williams, Robertson \& Johnson, 2013). Kontrol glikemik yang lebih buruk dan tingkat retinopati yang lebih tinggi terkait erat dengan literasi kesehatan yang tidak adekuat pada pasien perawatan primer dengan diabetes tipe 2 (Schillinger, Grumbach, Piette, Wang, Osmond, Daher, Palacios, Sullivan \& Bindman, 2002; Brega et al, 2012). Usia menjadi salah satu factor yang memiliki efek terhadap keterampilan literasi seseorang (Levinthal, Morrow, Tu, Wu dan Murray, 2008; Santosa, 2012). Hal ini dikaitkan dengan penurunan kemampuan kognitif dan sensoris lansia terkait penuaan.
Penurunan kemampuan berpikir ini akan mempengaruhi kemampuan dalam membaca dan memahami informasi (Kaholokula, Townsend, Ige, Sinclair, Mau, Leake \& Hughes, 2013). Data empiris mengenai tingkat literasi kesehatan dan factor yang mempengaruhi literasi kesehatan di Kota Manado masih terbatas oleh karena itu peneliti tertarik untuk melakukan kajian mengenai factor-faktor yang mempengaruhi tingkat literasi kesehatan pada penderita DM Tipe 2.

\section{METODE PENELITIAN}

Penelitian ini merupakan penelitian kuantitatif dengan pendekatan studi cross sectional yang dilakukan di 12 Puskesmas di Kota Manado.

Subjek Penelitian dan Prosedur

Subjek dalam penelitian ini adalah peserta Prolanis penderita Diabetes Mellitus ( $\mathrm{N}=52)$ berusia $\geq 45$ tahun. Peserta yang kurang dari satu tahun mengikuti Prolanis, tidak bisa membaca instrumen penelitian dan yang terlalu sakit untuk ikut serta dieksklusi dari penelitian. Pengambilan sampel menggunakan teknik purposive sampling. Pengumpulan data dilakukan melalui kuesioner. Responden yang bersedia berpartisipasi dalam penelitian diberikan informed consent setelah sebelumnya diberikan penjelasan terkait tujuan dan manfaat penelitian.

Pengambilan Data

Kuesioner determinan literasi kesehatan dipakai untuk mengumpulkan data terkait faktor yang mempengaruhi literasi kesehatan yaitu faktor usia, jenis kelamin, etnis, bahasa, pendidikan, status pekerjaan, penghasilan, akses pelayanan kesehatan dan akses informasi kesehatan. Pengukuran literasi kesehatan menggunakan kuesioner Adult Literacy for Diabetic (ALD) yang telah dimodifikasi dan diadaptasi ke bahasa Indonesia oleh Lusiana (2015) dan dinyatakan valid. Kuesioner ini terdiri dari penilaian kemampuan fungsional membaca istilah medis dan kemampuan memahami istilah medis. Istilah medis yang dipakai merupakan istilah medis berkaitan dengan Diabetes yang 
berjumlah delapan kata. Apabila responden mampu menyebutkan dan menjelaskan arti kata tersebut dengan benar maka masingmasing untuk kemampuan membaca dan memahami istilah medis diberi skor satu dan skor nol apabila salah. Skor total responden kemudian dikategorikan menjadi tinggi (nilai skor total $\geq 4$ ) dan rendah (nilai skor total < 4). Tingkat literasi kesehatan secara keseluruhan baik kemampuan membaca maupun memahami dikategorikan lagi menjadi kategori tinggi, marginal dan rendah. Literasi kesehatan rendah apabila kemampuan membaca rendah-kemampuan memaknai rendah, kategori marginal apabila kemampuan membaca tinggi - kemampuan memaknai rendah atau kemampuan membaca rendah- kemampuan memaknai tinggi dan dikatakan kategori tinggi apabila kemampuan membaca tinggi-kemampuan memaknai tinggi.

\section{Analisis Data}

Uji Pearson chi-square digunakan untuk menilai hubungan faktor usia, etnis, akses pelayanan kesehatan dan akses informasi kesehatan dengan tingkat literasi kesehatan sedangkan untuk faktor jenis kelamin, bahasa, pendidikan, pekerjaan serta penghasilan dianalisis menggunakan uji statistik Mann Whitney.

\section{HASIL}

\section{Karakteristik Responden}

Tabel 1 menunjukkan distribusi karakteristik responden. Sebagian besar responden adalah wanita. Rentang usia terbanyak $\geq 60$ tahun. Lebih dari separuh menggunakan bahasa Indonesia dalam percakapan sehari-hari, memiliki tingkat pendidikan yang rendah, tidak bekerja dan sebagian besar berpenghasilan dibawah UMR (rendah). Data mengenai akses pelayanan kesehatan pada penelitian ini dinilai dari keterjangkauan jarak ke Puskesmas, sarana dan biaya transportasi untuk mencapai Puskesmas serta ketersediaan petugas kesehatan. Responden diminta memberikan respon atas pernyataanpernyataan yang dibuat dalam skala Likert. Jawaban responden diberi skor berdasarkan responnya yaitu sangat setuju diberi skor 4 , setuju $=3$, tidak setuju $=2$ dan sangat tidak setuju $=1$. Skor ini kemudian dijumlahkan menjadi skor akses pelayanan kesehatan responden. Data ini kemudian dikelompokkan menjadi dua berdasarkan nilai tengah total skor akses pelayanan kesehatan. Jika skor responden < median maka dikategorikan ke dalam akses sulit sebaliknya kategori akses mudah jika skornya $\geq$ median. Nilai median skor akses pelayanan kesehatan responden adalah 16 (95\% CI: 11-20) maka hasil pengelompokkan data akses pelayanan kesehatan seperti yang ada pada tabel 1. Dari tabel 1 dapat dilihat bahwa bahwa lebih banyak responden yang mengatakan sulit untuk mendapatkan akses pelayanan kesehatan $(65,4 \%)$.

Pada penelitian ini, akses informasi kesehatan dilihat dari banyaknya sumber informasi kesehatan, frekuensi mendapat informasi kesehatan dari sumber-sumber tersebut dan kemudahan informasi untuk dimengerti serta reliabilitas informasi tersebut dalam sebulan terakhir. Masing-masing diberi skor sebagai berikut : pernah menerima informasi $=1$, tidak pernah menerima $=0$; mudah dimengerti $=2$, sebagian dimengerti $=1$, tidak mudah mengerti $=0$; dapat dipercaya $=2$, sebagian dipercaya $=1$ dan tidak dapat dipercaya $=0$. Jawaban responden atas pertanyaanpertanyaan ini diberi skor berdasarkan responnya. Total skor responden menjadi skor akses informasi kesehatan. Nilai rata-rata skor akses informasi kesehatan responden adalah 3,94 dan nilai mediannya 4 (95\% CI: 3,374,52) dengan standar deviasi sebesar 2,06. Skor terendah adalah 0 sedangkan yang tertinggi adalah 8. Data ini kemudian dikelompokkan menjadi dua kategori dengan batas nilai tengah. Jika skor responden $\geq$ median dikategorikan akses informasi tinggi sedangkan jika skor responden < median maka dikategorikan ke dalam akses informasi rendah. Responden yang memiliki akses informasi kesehatan yang rendah sebanyak $(53,8 \%)$. 


\begin{tabular}{ccccc}
\hline \multirow{2}{*}{$\begin{array}{c}\text { Skor } \\
\text { Total }\end{array}$} & \multicolumn{2}{c}{ LAD-I } & \multicolumn{2}{c}{ LAD-II } \\
\cline { 2 - 5 } & Jumlah & $\mathbf{( \% )}$ & Jumlah & $\mathbf{( \% )}$ \\
\hline 0 & 1 & 1,9 & 2 & 3,9 \\
1 & 0 & 0 & 9 & 17,3 \\
2 & 6 & 11,5 & 11 & 21,2 \\
3 & 5 & 9,6 & 6 & 11,5 \\
4 & 7 & 13,5 & 8 & 15,3 \\
5 & 11 & 21,2 & 6 & 11,5 \\
6 & 7 & 13,5 & 3 & 5,8 \\
7 & 8 & 15,3 & 5 & 9,6 \\
8 & 7 & 13,5 & 2 & 3,9 \\
\hline Jumlah & 52 & 100 & 52 & 100 \\
\hline
\end{tabular}

Tabel 1. Karakteristik Responden $(\mathbf{N}=52)$

\begin{tabular}{|c|c|}
\hline Determinan Literasi Kesehatan & $\%$ \\
\hline \multicolumn{2}{|l|}{ Usia } \\
\hline Pra Lansia (45-59 tahun) & 48,1 \\
\hline Lansia ( $\geq 60$ tahun) & 51,9 \\
\hline \multicolumn{2}{|l|}{ Jenis Kelamin } \\
\hline Laki-laki & 23,1 \\
\hline Perempuan & 76,9 \\
\hline \multicolumn{2}{|l|}{ Etnis } \\
\hline Suku Mayoritas & 51,9 \\
\hline Suku Minoritas & 48,1 \\
\hline \multicolumn{2}{|l|}{ Bahasa } \\
\hline Bahasa Daerah & 13,5 \\
\hline Bahasa Indonesia & 86,5 \\
\hline \multicolumn{2}{|l|}{ Pendidikan } \\
\hline Rendah (<SMP) & 57,7 \\
\hline Tinggi ( $\geq$ SMP) & 42,3 \\
\hline \multicolumn{2}{|l|}{ Status Pekerjaan } \\
\hline Bekerja & 7,7 \\
\hline Tidak Bekerja & 92,3 \\
\hline \multicolumn{2}{|l|}{ Penghasilan } \\
\hline Tinggi ( $\geq$ UMP) & 26,9 \\
\hline Rendah (<UMP) & 73,1 \\
\hline $\begin{array}{l}\text { Akses Pelayanan Kesehatan } \\
\text { Mudah } \\
\text { Sulit }\end{array}$ & $\begin{array}{l}34,6 \\
65,4\end{array}$ \\
\hline \multicolumn{2}{|l|}{ Akses Informasi Kesehatan } \\
\hline Tinggi & 46,2 \\
\hline Rendah & 53,8 \\
\hline
\end{tabular}

\section{Tingkat Literasi Kesehatan Responden}

Hasil analisis univariat didapatkan rata-rata skor LAD-I (kemampuan fungsional membaca istilah medis) responden adalah 5,08 (95\% CI: 4,52 - 5,64) dan rata-rata skor LAD-II (kemampuan memahami istilah medis) adalah 3 dengan nilai minimum 0 dan nilai maksimum 8 seperti ditunjukkan pada gambar 5 dan gambar 6. Distribusi total skor LAD tercantum pada tabel 2.

Tabel 2 Skor Total LAD-I dan LAD-II Responden

Keterangan: LAD-I = kemampuan membaca istilah medis; LAD-II= kemampuan memahami istilah medis

Dari tabel 2 terlihat bahwa hanya 1 responden yang tidak dapat membaca keseluruhan istilah medis dan hanya dua istilah medis yang paling banyak dipahami responden.

Skor total responden kemudian dikategorikan menjadi tinggi (nilai skor total $\geq 4$ ) dan rendah (nilai skor total < 4).

Tabel berikut menggambarkan distribusi tingkat literasi kesehatan responden setelah dikategorikan.

Tabel 3

Tingkat Literasi Kesehatan Responden (LAD-I dan LAD-II) berdasarkan kategori tinggi dan rendah

\begin{tabular}{ccccc}
\cline { 2 - 5 } Kategori & \multicolumn{2}{c}{ LAD-I } & \multicolumn{2}{c}{ LAD-II } \\
\cline { 2 - 5 } & Jumlah & $\%$ & Jumlah & $\%$ \\
\hline Tinggi & 33 & 63,5 & 16 & 69,8 \\
Rendah & 19 & 36,5 & 36 & 30,2 \\
Jumlah & 52 & 100 & 52 & 100 \\
\hline
\end{tabular}

Keterangan: LAD-I = kemampuan membaca istilah medis; LAD-II = kemampuan memahami istilah medis

Tabel 3 menunjukkan bahwa tingkat literasi kesehatan responden dalam hal membaca istilah medis (LAD-I) sebagian besar $(63,5 \%)$ memiliki tingkat literasi kesehatan tinggi sedangkan untuk kemampuan memahami istilah medis (LAD-II) justru sebaliknya. Sebagian besar responden memiliki literasi kesehatan rendah $(69,2 \%)$.

Hasil ini kemudian diinterpretasikan lagi menjadi kategori tinggi, marginal dan rendah dimana dikatakan rendah apabila kemampuan membaca rendah dan kemampuan memaknai rendah, kategori marginal apabila kemampuan membaca tinggi - kemampuan memaknai rendah atau kemampuan membaca rendah kemampuan memaknai tinggi dan dikatakan kategori tinggi apabila kemampuan membaca tinggi-kemampuan memaknai tinggi. Adapun hasil yang didapatkan yaitu seperti pada tabel 4 berikut ini. 
Tabel 4

Distribusi Tingkat Literasi Kesehatan Responden Berdasarkan Kategori Tinggi, Marginal, Rendah

\begin{tabular}{ccc}
\hline $\begin{array}{c}\text { Tingkat } \\
\text { Literasi Kesehatan }\end{array}$ & Jumlah & Persentase (\%) \\
\hline Tinggi & 15 & 28,8 \\
Marginal & 18 & 34,6 \\
Rendah & 19 & 36,5 \\
\hline Jumlah & 52 & 100 \\
\hline
\end{tabular}

Data distribusi tingkat literasi kesehatan responden menunjukkan bahwa distribusi kemampuan literasi kesehatan tinggi, marginal dan rendah tidak begitu jauh berbeda. Walaupun demikian lebih banyak responden masuk ke dalam kategori literasi kesehatan yang rendah (36,5\%), disusul kategori marginal $(34,6 \%)$ dan lebih sedikit yang memiliki tingkat literasi tinggi $(28,8 \%)$.

\section{Faktor Yang Berhubungan Dengan Literasi Kesehatan}

Tabel berikut akan menggambarkan hasil analisis bivariat faktor yang berhubungan dengan tingkat literasi kesehatan.

Tabel 5

Faktor Yang Berhubungan Dengan Literasi Kesehatan

\begin{tabular}{|c|c|c|c|c|c|c|c|}
\hline Bekerja & 1 & 25 & 1 & 25 & 2 & 50 & $0,412 \div$ \\
\hline Tidak Bekerja & 18 & 37,5 & 17 & 35,4 & 13 & 27,1 & \\
\hline Total & 19 & 62,5 & 18 & 60,4 & 15 & 77,1 & \\
\hline \multicolumn{8}{|l|}{ Penghasilan } \\
\hline Tinggi & 4 & 28,6 & 3 & 21,4 & 7 & 50 & \multirow[t]{2}{*}{$0,128+$} \\
\hline Rendah & 15 & 39,5 & 15 & 39,5 & 8 & 21,1 & \\
\hline Total & 19 & 67,1 & 18 & 60,9 & 15 & 71,1 & \\
\hline \multicolumn{8}{|l|}{ Akses } \\
\hline \multicolumn{8}{|l|}{ Pelayanan } \\
\hline \multicolumn{8}{|l|}{ Kesehatan } \\
\hline $\begin{array}{l}\text { Mudah } \\
\text { Dijangkau }\end{array}$ & 9 & 50 & 6 & 33,3 & 3 & 16,7 & \multirow[t]{2}{*}{$0,247 \dagger$} \\
\hline $\begin{array}{l}\text { Sulit } \\
\text { Dijangkau }\end{array}$ & 10 & 29,4 & 12 & 35,3 & 12 & 35,3 & \\
\hline Total & 19 & 79,4 & 18 & 68,6 & 15 & 52 & \\
\hline \multicolumn{8}{|l|}{ Akses } \\
\hline \multicolumn{8}{|l|}{ Informasi } \\
\hline \multicolumn{8}{|l|}{ Kesehatan } \\
\hline $\begin{array}{l}\text { Mudah } \\
\text { Dijangkau }\end{array}$ & 9 & 37,5 & 7 & 29,2 & 8 & 33,3 & \multirow[t]{2}{*}{$0,703 \dagger$} \\
\hline $\begin{array}{l}\text { Sulit } \\
\text { Dijangkau }\end{array}$ & 10 & 35,7 & 11 & 39,3 & 7 & 25 & \\
\hline Total & 19 & 72,3 & 18 & 68,5 & 15 & 58,3 & \\
\hline
\end{tabular}

Dari berbagai faktor yang telah dianalisa, hanya usia yang memiliki hubungan bermakna dengan tingkat literasi kesehatan dimana nilai $\mathrm{p}<0,05$.

Tingkat literasi kesehatan yang rendah terdapat pada $12(44,4 \%)$ responden berusia $\geq 60$ tahun dan 7 (28\%) responden berusia pra lansia. Responden perempuan yang memiliki literasi kesehatanyang tinggi sebanyak 14 (35\%) orang sedangkan laki-laki $4(33,3 \%)$ orang.

Diantara responden dengan latar belakang suku Minahasa, terdapat 11 (44\%) responden yang memiliki literasi kesehatan yang tinggi. Pada responden dengan latar belakang suku lainnya terdapat $4(14,8 \%)$ yang tingkat literasi kesehatannya tinggi. Jumlah responden yang menggunakan bahasa Indonesia sebagai bahasa utama dalam percakapan sehari-hari yang memiliki tingkat literasi kesehatanbaik rendah, marginal maupun tinggi masingmasing jumlahnya sama yaitu $15 \quad(33,3 \%)$ responden.

Dari kelompok yang memiliki tingkat pendidikan tinggi tidak ada yang memiliki literasi kesehatanyang rendah $(0,0 \%)$. Di antara responden yang tingkat pendidikannya rendah ada $13(26,5 \%)$ yang memiliki tingkat literasi kesehatan tinggi. Sebanyak 18 (37,5\%) responden yang tidak bekerja memiliki tingkat literasi kesehatanyang rendah dan diantara responden yang bekerja 1 orang (25\%) yang memiliki tingkat literasi kesehatanrendah dan 
$15(39,5 \%)$ responden yang berpenghasilan rendah memiliki tingkat literasi kesehatanyang rendah.

Pada responden yang memiliki akses pelayanan kesehatan yang mudah, terdapat 9 $(50 \%)$ orang yang memiliki literasi kesehatanrendah. Diantara responden yang aksesnya sulit, terdapat $10(29,4 \%)$ orang yang tingkat literasi kesehatannya rendah.

\section{PEMBAHASAN}

Hasil penelitian menunjukan bahwa hanya faktor usia yang memiliki hubungan bermakna dengan tingkat literasi kesehatan. Hal ini mungkin terjadi karena sebagian besar subjek dalam penelitian ini termasuk kategori usia lanjut sehingga faktor lain menjadi seperti tidak berkontribusi secara langsung terhadap literasi kesehatan pasien.

Penurunan kemampuan berpikir seiring proses penuaan serta rentang waktu yang lama sejak pendidikan terakhir akan mempengaruhi kemampuan dalam membaca dan memahami informasi (Shah, West, Bremmeyr dan Savoy-Moore, 2010). Jadi sekalipun akses pelayanan dan informasi penderita DM tipe 2 sangat mudah namun karena faktor usia inilah membuat mereka kesulitan memahami informasi kesehatan tersebut.

\section{SIMPULAN}

Tingkat literasi kesehatan penderita Diabetes Melitus Tipe 2 di Kota Manado tahun 2017 sebagian besar rendah. Faktor usia memiliki hubungan bermakna dengan tingkat literasi kesehatan penderita DM Tipe 2.

Petugas kesehatan perlu melakukan pengkajian terlebih dahulu tentang tingkat literasi kesehatan untuk memberikan informasi sesuai dengan tingkat literasi dan kebutuhan pasien tersebut.

\section{DAFTAR PUSTAKA}

1. Al Sayah, F., Majumdar, S. R., Williams, B., Robertson, S., \& Johnson, J. A. (2013).
Health literacy and health outcomes in diabetes: A systematic review. Journal of General Internal Medicine, 28(3), 444-52. doi:http://dx.doi.org/10.1007/s11606-0122241-z

2. Bennett, I. M., Chen, J., Soroui, J. S., \& White, S. (2009). The contribution of health literacy to disparities in self-rated health status and preventive health behaviors in older adults. The Annals of Family Medicine, 7(3), 204-211.

3. Bosworth, H. B., Olsen, M. K., Dudley, T., Orr, M., Goldstein, M. K., Datta, S. K., . . . Oddone, E. Z. (2009). Patient education and provider decision support to control blood pressure in primary care: A cluster randomized trial. The American Heart Journal, 157(3), 450-456. doi:http://dx.doi.org/10.1016/j.ahj.2008.11 .003

4. Brega, A.G., Ang, A., Vega, W., Jiang, L., Beals, J., Mitchell, C.M., ..., Roubideaux, Y. (2012). Mechanisms underlying the relationship between health literacy and glycemic control in American Indians and Alaska natives. Patient Education and Counseling, 88(1), 61-68.doi: 10.1016/j.pcc.2012.03.008

5. Burns, N \& Gorve, S. K. (2011). Understanding nursing research: building an evidence based practice $\left(5^{\text {th }}\right.$ ed). Maryland: Elsevier Saunders

6. Creswell, J. W. (2013). Research design : qualitative, quantitative, and mixed methods approaches $\left(4^{\text {th }} \mathrm{ed}\right)$. Los Angeles : SAGE

7. IDF. (2013). International Diabetes Federations: Diabetes Atlas. Retrieved from https://www.idf.org/elibrary/epidemiology-research/diabetesatlas.html

8. Idris, F. (2014). Pengintegrasian Program Preventif Penyakit Diabetes Melitus Tipe 2 PT Askes (Persero) ke Badan Penyelenggara Jaminan Sosial Kesehatan (BPJS Kesehatan). Journal of The Indonesia Medical Association, 64(3).

9. Kaholokula, J. K., Townsend, C. K. M., Ige, A., Sinclair, K. A., Mau, M. K., Leake, A., ... Hughes, C. (2013). Sociodemographic, behavioral, and biological variables related 
to weight loss in native hawaiians and other pacific islanders. Obesity, 21(3), E196-E203. doi:http://dx.doi.org/10.10021oby.20038

10. Kemenkes. (2013). Buletin Jendela Data Informasi Kesehatan. Retrieved from http://www.depkes.go.id/resources/downl oad/pusdatin/infodatin/infodatinlansia.pdf

11. Lee, T. W., Lee, S. H., Kim, H. H., \& Kang, S. J. (2012). Effective intervention strategies to improve health outcomes for cardiovascular disease patients with low health literacy skills: A systematic review. Asian Nursing Research, 6(4), 128-136. doi:http://dx.doi.org/10.1016/j.anr.2012.0 9.001

12. Levinthal, B. R., Morrow, D. G., Tu, W., Wu, J., \& Murray, M. D. (2008). Cognition and health literacy in patients with hypertension. Journal of General Internal Medicine, 23(8), 1172-6. doi:http://dx.doi.org/10.1007/s11606008-0612-2

13. Lusiana, Evi. (2015). ANALISIS HUBUNGAN DIABETIC LITERACY DENGAN SELF MANAGEMENT PADA PASIEN DIABETES MELITUS DI RS. UNIVERSITAS HASANUDDIN MAKASSAR. Retrieved from http://repository.unhas.ac.id:4002/digilib/ gdl.php?mod=browse \&op=read\&id

14. Mancuso, C. A., M.D., \& Rincon, M., M.A. (2006). Impact of health literacy on longitudinal asthma outcomes. Journal of General Internal Medicine, 21(8), 813-7. doi:http://dx.doi.org/10.1111/j.15251497.2006.00528.x. Diakses 9 November 2015 dari http://search.proquest.com/docview/2081 45949/abstract/BAAC8E27A3E3497FPQ $/ 1$ ?accountid $=39870$

15. McCleary-Jones, V. (2011). Health literacy and its association with diabetes knowledge, self-efficacy and disease selfmanagement among african americans with diabetes mellitus. $A B N F$ Journal, 22(2), 25-32. Retrieved from http://search.proquest.com/docview/8668 47182? accountid $=39870$
16. Morrow, D. G., Weiner, M., Steinley, D., Young, J., \& Murray, M. D. (2007). Patients' health literacy and experience with instructions influence preferences for heart failure medication instructions. Journal of Aging and Health, 19(4), 575-593.

17. Nath, C. (2007). Literacy and diabetes selfmanagement. American Journal of Nursing, 107(6 Suppl), 43-49.

18. Nielsen-Bohlman, L. (2004). Health Literacy: A Prescription to End Confusion. Washington, DC, USA: National Academies Press. Retrieved from http://www.ebrary.com

19. Nutbeam, D. (2000). Health literacy as a public health goal: a challenge for contemporary health education and communication strategies into the $21 \mathrm{st}$ century. Health Promotion International, 15(3), 259-267.

20. Omachi, T. A., Sarkar, U., Yelin, E. H., Blanc, P. D., \& Katz, P. P. (2013). Lower health literacy is associated with poorer health status and outcomes in chronic obstructive pulmonary disease. Journal of General Internal Medicine, 28(1), 74-81. doi:http://dx.doi.org/10.1007/s11606-0122177-3

21. Pawlak, R. (2005). Economic considerations of health literacy. Nursing Economics, 23(4), 173-80, 147. Retrieved from

https://search.proquest.com/docview/2369 38290?accountid $=39870$

22. Putri, N. H. K., \& Isfandiari, M. A. (2013). Hubungan Empat Pilar Pengendalian DM Tipe 2 dengan Rerata Kadar Gula Darah. Jurnal Berkala Epidemiologi, 1(2), 234243.

23. Reed, S. D., Li, Y., Oddone, E. Z., Neary, A. M., Orr, M. M., Grubber, J. M., ... . Bosworth, H. B. (2010). Economic evaluation of home blood pressure monitoring with or without telephonic behavioral self-management in patients with hypertension. American Journal of Hypertension, 23(2), 142-8. doi:http://dx.doi.org/10.1038/ajh.2009.215

24. A. M., Orr, M. M., Grubber, J. M., . . . Bosworth, H. B. (2010). Economic evaluation of home blood pressure 
monitoring with or without telephonic behavioral self-management in patients with hypertension. American Journal of Hypertension, 23(2), 142-8. doi:http://dx.doi.org/10.1038/ajh.2009.21 5

25. Santosa, K.S. (2012). Faktor-faktor yang berhubungan dengan tingkat kemelekan kesehatan pasien di klinik dokter keluarga fakultas kedokteran universitas Indonesia Kiara DKI Jakarta. Tesis. Diakses dari lib.ui.ac.id/file?file=digital/20314376

26. Schillinger, D., Grumbach, K., Piette, J., Wang, F., Osmond, D., Daher, C., Palacios, J., Sullivan, G.D., Bindman, A.B. (2002). Association of Health Literacy With Diabetes Outcomes. JAMA, 288(4):475-482. doi:10.1001/jama.288.4.475

27. Sørensen, K., Van den Broucke, S., Fullam, J., Doyle, G., Pelikan, J., Slonska, Z., \& Brand, H. (2012). Health literacy and public health: a systematic review and integration of definitions and models. BMC public health, 12(1), 80.

28. Stableford, S., \& Mettger, W. (2007). Plain language: A strategic response to the health literacy challenge. Journal of Public Health Policy, 28(1), 71-93. Retrieved from http://search.proquest.com/docview/2333 68530? accountid $=39870$

29. van Keulen, H.,M., Mesters, I., Ausems, M., van Breukelen, G., Campbell, M., Resnicow, K., . . . de Vries, H. (2011). Tailored print communication and telephone motivational interviewing are equally successful in improving multiple lifestyle behaviors in a randomized controlled trial. Annals of Behavioral Medicine, 41(1), 104-18. doi:http://dx.doi.org/10.1007/s12160-

010-9231-3 